\title{
Resurgence of an Australasian Prehospital Journal
}

\author{
Dr Malcolm Boyle
}

Affiliation:

Editor, Australasian Journal of Paramedicine

As the new editor of the former Journal of Emergency Primary Health Care, now the Australasian Journal of Paramedicine, I welcome you to the first issue of 2013 and a new start for the journal. The Australasian Journal of Paramedicine (AJP) is the official open access, peer-reviewed, international journal of Paramedics Australasia (PA), the peak professional body for paramedics across Australasia.

With a new editor and editorial team comes a new set of aims and direction for the journal in its resurgence. What has happened in the past is history. Now there is only a view to the future and the direction the editorial board will take the journal.

With the new journal name and fresh start comes a new presentation of the published material. The change to the presentation of the different article types is designed to provide a more modern and contemporary look.

The AJP will still be an open access, peerreviewed, international journal to advance and promote the science of prehospital/out-of-hospital care research, covering areas such as:

- first aid,

- disaster preparedness,

- disaster management/response,

- military/combat environment,

- non-emergency management,

- education,

- clinical practice,

- policy,

- service delivery, and

- management.

The AJP will not limit itself to only prehospital/outof-hospital manuscripts but will accept manuscripts of interest from the hospital emergency department and community healthcare settings.

One of the AJP aims is to reduce the loss of small yet important studies and articles. The AJP therefore provides a repository for short publications, case studies, case series, incremental updates of previous work, results of individual experiments, results of confirmatory and 'negative' results, and other related research outcomes that currently lack a suitable repository. Reviewers will be asked not to reject a manuscript unless there are extenuating circumstances, but to provide quality feedback to the authors so it is a learning experience and that the manuscript can be improved to enable publication.

Over time there will be changes to the journal web site to continue the theme of a new start and new look. The journal will not be static but will change over time to meet the publishing needs of the burgeoning prehospital care profession. The journal will publish four issues per year plus supplementary issues for specific or special events, such as abstracts from the Paramedics Australasia annual international conference.

I look forward to your ongoing support of the journal. 